\title{
Formação de professores: A trajetória da docência universitária no curso de Licencia- tura em Pedagogia da UAB/UECE
}

\author{
Teacher education: The path of university teaching in the Pedagogy BA Program at \\ $\mathrm{UAB} / \mathrm{UECE}$
}

\author{
Mayara Alves Loiola Pacheco \\ e-mail: mayara.loiola@aluno.uece.br \\ Universidade Estadual do Ceará-UECE. Brasil \\ Rachel Rachelley Matos Monteiro (iD) \\ e-mail: rachel.monteiro@aluno.uece.br \\ Universidade Estadual do Ceará-UECE. Brasil
}

Alana Dutra do Carmo iD

e-mail: alana.dutra@aluno.uece.br

Universidade Estadual do Ceará-UECE. Brasil

Antonio Germano Magalhães Junior (iD

e-mail: germano.junior@uece.br

Resumo

Universidade Estadual do Ceará-UECE. Brasil

A educação a distância apresenta características específicas, rompendo com a concepção da presencialidade no processo de ensino-aprendizagem. Este trabalho é oriundo de uma pesquisa sobre a formação dos professores e a trajetória profissional de docentes do curso de Pedagogia na modalidade de educação a distância da Universidade Aberta do Brasil. Tivemos como objetivo compreender o percurso formativo dos professores do Curso de Licenciatura em Pedagogia da UAB de uma Instituição de Ensino Superior para o exercício da docência em um curso de educação a distância. O presente estudo é de abordagem qualitativa, que tem como método o estudo de caso. Tivemos uma amostra de 10 docentes que ministraram as disciplinas de Avaliação Educacional e 5 que estiveram à frente da disciplina de Didática Geral, mapeamos a sua formação inicial, continuada e complementar em busca de compreender a trajetória profissional de cada um destes docentes, em especial, de «profissionais formadores». Concluímos que a formação dos professores e a sua trajetória profissional se constituem como essenciais na atuação docente e, neste estudo, com as compreensões teóricas e práticas sobre a modalidade educacional, o nosso objetivo de compreender o percurso formativo dos professores do curso de Licenciatura em Pedagogia da UAB foi alcançado, nos permitindo realizar uma reflexão sobre as trajetórias profissionais e a constituição do «ser professor».

Palabras-chave: educação; pedagogia; formação profissional; educação a distância.

\section{Abstract}

Distance education has specific characteristics, breaking with the conception of presence in the teaching-learning process. This work comes from research on teacher education and the professional trajectory of teachers of the Pedagogy course in the distance education modality of the Open University of Brazil. We aimed to understand the formative path of teachers of the Pedagogy Degree Course at UAB of a Higher Education Institution for the exercise of teaching in a distance education course. The present study is a qualitative approach, which has followed the case study method. We had a sample of 10 teachers who taught the Educational Assessment subjects and 5 who were at the head of the General Didactics subject. We mapped their initial, continuous and complementary training in order to understand the professional trajectory of each of these teachers, in particular, of «professional trainers». We conclude that the formation of teachers and their professional trajectory are essential in teaching performance and, in this study, with the theoretical and practical understandings about the educational modality, our goal to understand the formative path of teachers of the Degree in Pedagogy UAB was achieved, allowing us to reflect on the professional trajectories and the constitution of «being a teacher».

Keywords: education; pedagogy; teacher education; distance education.

Recibido / Received: 22-08-2019

Aceptado / Accepted: 28-11-2019

Publicación en línea / Published online: 30-03-2020

Cómo referenciar este artículo / How to reference this article:

Loiola Pacheco, M. A., Matos Monteiro, R. R., do Carmo, A. D., \& Magalhães Junior, A. G. (2020). Formação de professores: a trajetória da docência universitária no curso de licenciatura em Pedagogia da UAB/UECE. Tendencias Pedagógicas, 36, pp. 129-140. doi: 10.15366/tp2020.36.10 


\section{Introdução}

As discussões sobre a formação de professores se tornam presentes para que se possa perceber e validar os caminhos percorridos pelo contexto educacional, em especial, a formação nos cursos de licenciatura. Quando discutimos sobre o tema «formação dos professores dos cursos a distância», procuramos buscar compreender as especificidades dessa modalidade educacional. Partindo do fato de que um curso de licenciatura tem como foco a formação de professores, entendemos que aqueles que formam os futuros professores são essenciais neste processo.

Esta pesquisa buscou compreender como os docentes universitários de um curso de Licenciatura em Pedagogia constituíram formações específicas na modalidade a distância durante o seu percurso formativo. Em especial, por cursos em nível de formação inicial e continuada. Entendemos por pertinente a capacitação do docente que tenha realizado cursos específicos voltados ao exercício profissional em EaD.

Assim, tivemos como objetivo mapear o percurso formativo dos professores do curso de Licenciatura em Pedagogia da UAB de uma Instituição de Ensino Superior para o exercício da docência no ensino superior em um curso de educação a distância.

A relevância deste estudo surge pela necessidade de pensarmos em uma formação de professores reflexiva e crítica perante o ato educativo, no sentido dado por Freire (1970) de que a formação deve conduzir ao desenvolvimento de cidadãos que sejam capazes de analisar suas realidades social, histórica e cultural, criando possibilidades para transformá-la, conduzindo alunos e professores a uma autonomia e emancipação. Esta pesquisa emerge dos questionamentos e discussões sobre a formação de professores e os saberes docentes de um grupo de pesquisa de um Programa de Pós-Graduação em Educação de uma Instituição Pública do Estado do Ceará.

O presente estudo é de abordagem mista. A pesquisa de métodos mistos segundo Johnson, Onwuegbuzie e Turner (2007) é o tipo de pesquisa em que um pesquisador ou um grupo de pesquisadores combinam elementos de abordagem de pesquisa qualitativa e quantitativa para o objetivo de ampliar e aprofundar o entendimento e a ratificação. Nesse caso ou autores consideram os métodos mistos como uma metodologia que uni os pontos de vista às inferências e incluí a combinação de pesquisas qualitativa e quantitativa. Dal-Farra e Lopes (2013) ressaltam que a construção de estudos com métodos mistos pode proporcionar pesquisas de grande relevância para a Educação como corpus organizado de conhecimento.

Em concordância com a abordagem mista, adotou-se como método o estudo de caso para compreender o lócus pesquisado. O estudo de caso, segundo Ventura (2007), é adotado na investigação de fenômenos das mais diversas áreas do conhecimento, podendo ser visto como caso clínico, técnica psicoterápica, metodologia didática ou modalidade de pesquisa. Para Yin (2015), o estudo de caso representa uma investigação empírica e compreende um método abrangente, com a lógica do planejamento, da coleta e da análise de dados. Pode incluir tanto estudo de caso único quanto de múltiplos, assim como abordagens quantitativas e qualitativas de pesquisa. Segundo Despresbiteris (1999), o estudo de caso busca a particularidade e a complexidade de um caso singular para se chegar à compreensão do que acontece em circunstâncias específicas e permite obter uma grande quantidade de informações sobre o caso escolhido e posteriormente ter a possibilidade de aprofundar seus aspectos.

A coleta e a análise de dados foram realizadas por meio da pesquisa bibliográfica e documental. Segundo Gil (2002, p. 44), «a pesquisa bibliográfica é desenvolvida com base em material já elaborado, constituído principalmente de livros e artigos científicos, permitindo ao investigador abranger uma quantidade maior de fenômenos a partir do que já foi produzido sobre o tema pesquisado». E a pesquisa documental, conforme Gil (2002), assemelha-se à pesquisa bibliográfica, possuindo como diferença entre ambas a natureza das fontes. $\mathrm{Na}$ pesquisa documental, o pesquisador tem contato com materiais que não tiveram tratamento analítico ou que ainda podem ser reelaborados de acordo com a pesquisa.

Neste sentido, a presente pesquisa segue o recorte temporal de um estudo macro, que proporcionou dados pertinentes para a elaboração dessa pesquisa. Foi pesquisada a formação de docentes que ministraram as disciplinas de Didática Geral e Avaliação Educacional, entretanto por se tratar de um curso ofertado na modalidade a distância, o recorte histórico selecionado foi a turma de 2014, pois, devido à alta rotatividade dos docentes que atuam na modalidade de $\mathrm{EaD}$, decidiu-se por escolher a oferta mais recente por abranger professores que pudessem colaborar na realização da coleta dos dados. 
Partindo desse contexto, em contato com a coordenação do curso pesquisado, tivemos acesso aos nomes dos docentes, nos permitindo a análise de seus currículos lattes. Para a turma de 2014, tivemos uma quantidade de 5 docentes que ministram a disciplina de Avaliação Educacional e 5 docentes que lecionaram a disciplina de Didática Geral, totalizando 10 professores.

A pesquisa macro teve como foco analisar como se constituiu a formação inicial e acadêmica, seus saberes e suas práticas durante a sua trajetória docente. Este artigo visou pesquisar especificamente de quais formações complementares esses professores participaram e principalmente as formações específicas para sua atuação em disciplinas ofertadas na modalidade a distância.

Para tanto, dividimos este estudo em três momentos. O primeiro versará sobre os aspectos teóricos pertinentes às categorias «docência universitária» e «educação a distância»; o segundo tópico abordará sobre a formação continuada para professores de nível superior e, por fim, temos o mapeamento dos percursos formativos dos docentes pertinentes ao recorte desta pesquisa.

\section{A docência universitária e as particularidades dos cursos em educação a distância}

No transcorrer dos anos tenta-se conceituar a educação a distância (EaD) como modalidade de ensino que vem incorporando novas estratégias pedagógicas e tecnológicas à área da educação. Temos como concepção que a EaD pode ser definida também a partir da relação professor aluno ou ensino-aprendizagem mediada pedagogicamente e midiatizada por diversos materiais instrucionais e pela orientação tutorial. Isto é válido tanto para ambientes pedagógicos tradicionais como para aqueles que usam as novas tecnologias.

A educação a distância apresenta características específicas, rompendo com a concepção da presencialidade no processo de ensino-aprendizagem. Segundo Vidal, Maia e Gomes (2014), para a EaD o ato pedagógico não é mais centrado na figura do docente, e não parte mais do pressuposto de que a aprendizagem só acontece a partir de uma aula em que aluno e professor estejam no mesmo espaço/tempo. Os autores continuam discorrendo sobre as especificidades da $\mathrm{EaD}$, destacando o fato desta, na maioria das vezes, trabalhar com estudantes adultos e se utilizar de material autoinstrucional e estudo individualizado, em que o aluno aprende a aprender, a estudar a partir do seu esforço e por conta própria, desenvolvendo habilidades de independência e iniciativa.

Nesse novo âmbito surge por iniciativa do Ministério da Educação (MEC) a Universidade Aberta do Brasil (UAB) como um meio de inclusão pela oferta de educação superior a distância. Segundo Vidal et al. (2014), conhecedor de que a ampliação de vagas nas universidades públicas enfrentava sérias limitações, o MEC viu na UAB a possibilidade de democratizar, expandir e interiorizar o ensino superior público e gratuito no país, com apoio da educação a distância e a incorporação de novas metodologias de ensino, especialmente do uso de tecnologias digitais.

A UAB foi institucionalização pelo Decreto $n^{\circ} 5.800 / 2006$, que buscou incentivar as instituições públicas a participarem de programas de formação inicial e continuada de professores para educação básica que podiam ser ofertados na modalidade a distância. O programa UAB oferece cursos de graduação, sequenciais, de pós-graduação lato sensu e stricto sensu prioritariamente orientada para a formação de professores e a administração pública.

Para Almeida (2003, p. 1), «a universidade depara-se com desafios provocados pelas transformações, incertezas e complexidade da ciência, pelas demandas da sociedade do conhecimento e pela disseminação das TICs»". A universidade nessas circunstâncias vê-se desafiada a encarar a educação a distância com uma postura que permita a expansão de propostas inovadoras.

Estamos inseridos em um contexto social que não permite mais que a formação inicial de professores deixe de abordar o desenvolvimento tecnológico e a educação a distância como palco de trabalho de professores. Segundo Tavares (2001), a formação inicial de professores deve prenunciar a sua capacitação para uma educação continuada, além de formar o futuro professor para o uso pedagógico das tecnologias, principalmente da internet.

Distinta dos meios de comunicação tradicionais (livros, rádio, televisão, dentre outros), a internet possibilita uma interatividade entre professor, aluno e tecnologia. Não é correto, porém, concluir que todo curso de educação a distância baseado na internet está modificando a lógica tradicional, fazendo um uso interativo desta tecnologia. M. Silva (2006) explicita que dentro de um ambiente on-line valoriza-se a interação e a troca de informações entre professor e aluno no lugar da reprodução passiva de conteúdos através da oratória, mas esta postura não é determinada somente pela escolha tecnológica. 
Na educação a distância o desenvolvimento de Ambientes Virtuais de Aprendizagem (AVA's) tem se tornado uma prática constante. Para Silva (2006), os AVA's representam a sala de aula on-line. Esse ambiente é um conjunto de interfaces, ferramentas e estruturas decisivas para a construção da interatividade e da aprendizagem. Segundo Costa e Franco (2005), em geral a utilização desses ambientes não exige dos professores um domínio mais aprofundado de informática, sendo necessárias apenas poucas horas de cursos de formação para a utilização do ambiente.

Esse tipo de ambiente baseia-se na concepção de interatividade homem e máquina e na interação homem e homem, podendo utilizar máquinas como participação colaborativa, bidirecional e dialógica, pressupõe a compreensão de conhecimento como algo hipertextual, aberto a conexões, à integração de várias linguagens (sons, textos, imagens) e ancora-se na abordagem da educação como «um sistema aberto, com mecanismos de participação e descentralização flexíveis, com regras de controle discutidas pela comunidade e decisões tomadas por grupos interdisciplinares» (Silva, 2006, p. 9).

$O$ uso adequado dos AVAs para uma educação online realmente inovadora deve estimular a curiosidade, a colaboração, a resolução de problemas, a busca e a contextualização de informações (Moraes, 2002). Alguns modelos de educação on-line têm utilizado a internet somente como um local para disponibilizar materiais para um grande número de alunos, resultado de «práticas pedagógicas instrucionistas, tecnologicamente mais sofisticadas, mas pedagogicamente vazias e empobrecidas» (Moraes, 2002, p. 1).

A internet apresenta a possibilidade de interação e envolvimento entre professores e alunos no ambiente virtual de aprendizagem, ela vai muito além de um local para disponibilizar materiais de leitura. Moraes (2002) afirma que são necessárias novas teorias e metodologias que venham se contrapor ao modelo tradicional com a utilização dos ambientes interativos em suas potencialidades, possibilitando a construção de conhecimentos de forma individual e coletiva.

A alfabetização tecnológica do docente aparece como eixo central das discussões sobre a formação do professor para atuar na educação a distância. Para Sampaio e Leite (1999), a alfabetização tecnológica não se limita ao uso mecânico dos recursos tecnológicos, pois abrange o domínio crítico da linguagem tecnológica. Os professores devem conhecer bem os recursos disponíveis e ligá-los aos objetivos propostos. Para as autoras Sampaio e Leite (1999), quando as pessoas não são capacitadas para interpretar criticamente as informações e as diferentes linguagens que a tecnologia utiliza, a relação homem/tecnologia acaba tornando-se mais um fator de desigualdade social. Torna-se necessário preparar o professor para o uso pedagógico dessas tecnologias na formação.

Dessa forma, Silva (2006) complementa afirmando que o professor deve fazer a relação entre as habilidades técnicas, os métodos ativos de aprendizagem e as teorias educacionais que o ajudarão a refletir sobre a própria prática e a transformá-la, visando explorar as potencialidades pedagógicas das tecnologias em função da aprendizagem e da construção do conhecimento. Freire (2006, p. 47) insiste que «ensinar não é transferir conhecimento, mas criar as possibilidades para a sua própria produção ou a sua construção». Nessa direção, a formação deve excitar a curiosidade do aluno estimulando-o à pesquisa e à reflexão.

Seja qual for o ambiente onde o professor exerça sua docência, é importante que ele tenha um tempo para avaliar e refletir sobre sua atuação e a repercussão dela sobre a vida de seus alunos; essa reflexão sobre si também é uma reflexão sobre a prática docente. Quando o ensino é pensado como atividade reflexiva, o professor não é mais visto como técnico direcionado à aplicação das teorias científicas, mas é visto como profissional reflexivo com um papel ativo e com capacidade de resolver situações problemáticas concretas vivenciadas na própria prática. A reflexão durante e para ação contribui na análise sistemática que orienta ação (Schön, 2000). Schön propõe o desenvolvimento de uma «epistemologia da prática profissional» que situe as problemáticas técnicas e racional no campo da investigação reflexiva da ação.

A flexibilidade de tempo e espaço no trabalho do professor em cursos na modalidade a distância é um fator marcante. É na prática diária da docência na $\mathrm{EaD}$ que o professor vai construindo sua autonomia e suas estratégias de como lidar com as tecnologias, com os alunos, com a gestão e com o controle. $\mathrm{Na} \mathrm{EaD}$ o professor vai se adaptando à situação de estar sendo observado e de ter suas atividades controladas. Para Rocha (2006), o controle exercido pelos meios tecnológicos produz nos sujeitos uma sensação de atenção permanente. 
«O 'controlado' é um sujeito anônimo - qualquer um - que, em princípio, não sabe o que pode ou não ser feito. Para que não corramos, portanto, o risco de sermos surpreendidos por uma ação indesejada de um descontrolado, é que são utilizadas máquinas, tecnologias, mecanismos que impedem a realização de ações indesejadas e mantêm todos em estado de alerta. O discurso do controle acaba sendo justificado como forma de garantir a qualidade do ensino, a aprendizagem do aluno, o bom funcionamento do processo, fazendo com que tudo funcione como se deseja, como (parece) ser melhor para todos, para nossa conveniente convivência pacífica.» (Rocha, 2006, p. 88)

Assim sendo, à docência na educação a distância no ensino superior possui importantes responsabilidades tanto quanto à docência no ensino presencial. Nessa modalidade se destaca ainda a necessidade de uma formação mais especifica para o professor que contemple as especificidades com relação às ferramentas tecnológicas, que podem ser um fator positivo ou negativo nas aulas, dependendo de sua utilização.

Na seção seguinte apresentaremos as discussões teóricas sobre a formação continuada dos professores nos cursos de Educação a Distância.

3. Formação continuada de professores nos cursos de educação a distância: estudo de caso de uma Instituição de Ensino Superior

A formação dos professores surge nas implicações reais e imateriais sobre a necessidade discursiva em pensar o contexto educacional e uma formação baseada em princípios reflexivos e críticos da sociedade. Falar sobre docência universitária e a modalidade de ensino superior implica discutir sobre um perfil de profissionais docentes com formações e saberes que se materializam no decorrer da sua trajetória pessoal e profissional, ainda mais se falarmos sobre a formação dos professores dos cursos de educação a distância; é perceber caminhos e concepções acerca dessa docência. Segundo Gauthier, Mortineau, Desbiens, Malo e Simard (1998), entende-se que a docência é também compreendida a partir daquilo que os professores consideram pertinente para a sua prática: «O exercício de uma profissão implica, portanto, uma atividade intelectual - voltada tanto para a concepção como para a execução - que compromete a responsabilidade individual do agente» (p. 78).

É necessário destacarmos as modalidades de ensino superior nos modos presencial, semipresencial e a distância. O modo presencial organiza-se com os encontros entre professores e alunos em uma universidade, faculdade ou centro universitário regular, com aulas e programas em semestres definidos conforme o calendário da instituição. O semipresencial organiza-se a depender do vínculo com a instituição de ensino, podendo ser adotados encontros semanais, quinzenais ou mensais para as aulas presenciais e os outros encontros em uma plataforma virtual como o AVA. Os cursos a distância possuem algumas especificidades que assim como a semipresencial modifica-se de acordo com a instituição, podendo ter encontros periódicos presenciais com professores e/ou tutores, entendendo que o marco para esses cursos é a integralidade virtual no processo formativo.

Dessa forma, refletindo sobre a formação dos universitários que atuam no curso de licenciatura em Pedagogia EaD, a instituição investigada exemplifica que o professor formador precisa ser

«responsável pelas disciplinas. Estará à disposição para esclarecimento de dúvidas dos estudantes e/ou tutores a partir de cronograma estabelecido junto a cada docente. O professor será selecionado, prioritariamente, entre os docentes vinculados a UECE, considerando sua formação, aptidão e habilidade para conduzir a disciplina. Após a seleção, o professor deve participar do processo de formação sobre $\mathrm{EaD}$, produção de material didático para as disciplinas do curso, sistemática de acompanhamento presencial e a distância, mecanismos de avaliação para $\mathrm{EaD}$, questões relativas ao processo de orientação da monografia, etc.» (UECE, 2017, p. 31)

Com base nos requisitos que o professor formador precisa apresentar, é necessário pensar para além da formação inicial e continuada, é necessário perceber o "fazer-se docente" durante o seu percurso e prática formativa, constituindo um repertório de saberes docentes bem como afirma Gauthier, Mortineau, Desbiens, Malo e Simard (1998): 
«Pensar que ensinar consiste apenas em transmitir um conteúdo a um grupo de alunos é reduzir uma atividade tão complexa quanto o ensino a uma única dimensão, aquela que é mais evidente, mas é sobretudo engar-se-á refletir de forma mais profunda sobre a natureza desse ofício e dos outros saberes que lhe são necessários. Numa palavra, o saber do magister não se resume apenas ao conhecimento da matéria» (pp. 20-21).

Com o intuito de mapear os polos que se destinam à formação a distância na instituição na qual estamos explicitando os achados desta pesquisa e compreender a sua contribuição para a formação de profissionais capacitados nos diversos municípios cearenses, apresentamos o quadro abaixo com a oferta de cursos de graduação a distância por polos ${ }^{1}$ para o contexto cearense.

Quadro 1.

Polos e ofertas dos cursos de graduação a distância da IES

\begin{tabular}{|c|c|c|}
\hline \multicolumn{3}{|c|}{ Polos e ofertas dos cursos de graduação a distância da IES } \\
\hline Polo & Grau acadêmico & Cursos \\
\hline Aracoiaba & Licenciatura & Ciências Biológicas \\
\hline Barbalha & Licenciatura & Matemática \\
\hline Beberibe & Licenciatura & $\begin{array}{l}\text { Ciências Biológicas, Educação Física, } \\
\text { Computação, Geografia, Informática, } \\
\text { Química e Pedagogia }\end{array}$ \\
\hline Brejo Santo & Licenciatura/Bacharelado & $\begin{array}{l}\text { Computação, Física e Administração } \\
\text { Pública. }\end{array}$ \\
\hline Campos Sales & Licenciatura/Bacharelado & $\begin{array}{l}\text { Computação, Física e Administração } \\
\text { Pública. }\end{array}$ \\
\hline Caucaia & Licenciatura & $\begin{array}{l}\text { Educação Física, Computação, Geogra- } \\
\text { fia, Informática Matemática, Pedagogia, } \\
\text { Administração Pública e História }\end{array}$ \\
\hline Crateús & Bacharelado & Geografia \\
\hline Fortaleza & Licenciatura & $\begin{array}{l}\text { Computação, Matemática, Administra- } \\
\text { ção, Artes Visuais e História }\end{array}$ \\
\hline Iguatu & Bacharelado & História \\
\hline Itapipoca & Licenciatura/Bacharelado & $\begin{array}{l}\text { Ciências Biológicas, Computação, Geo- } \\
\text { grafia, Informática e Administração Pú- } \\
\text { blica }\end{array}$ \\
\hline Jaguaribe & Licenciatura/Bacharelado & $\begin{array}{l}\text { Ciências Biológicas, Computação, Fí- } \\
\text { sica, Geografia, Informática, Química, } \\
\text { Pedagogia E Administração Pública }\end{array}$ \\
\hline Limoeiro do norte & Licenciatura & Computação, Informática E Pedagogia. \\
\hline Maranguape & Licenciatura & $\begin{array}{l}\text { Ciências Biológicas, Física, Informática, } \\
\text { Pedagogia e Administração Pública }\end{array}$ \\
\hline Mauriti & Licenciatura / bacharelado & $\begin{array}{l}\text { Educação Física, Computação, Infor- } \\
\text { mática, Matemática, Química, Pedago- } \\
\text { gia e Administração Pública }\end{array}$ \\
\hline Missão velha & Licenciatura & Informática \\
\hline Orós & Licenciatura & $\begin{array}{l}\text { Geografia, Química, Pedagogia, Artes } \\
\text { Plásticas e Artes Visuais }\end{array}$ \\
\hline Piquet carneiro & Licenciatura & Matemática e Química \\
\hline Quixadá & Bacharelado & Administração \\
\hline
\end{tabular}

Conforme os estudos de García (1999, p. 23) «a formação de professores procura desenvolver nos docentes um estilo de ensino próprio e assumido refletidamente, de modo a produzir nos alunos uma aprendizagem significativa». Nesse sentido, falar sobre a docência dos professores no curso de EaD é perceber uma formação continuada com inquietações e ideias necessárias para a contribuição do

\footnotetext{
${ }^{1}$ Tivemos como fonte destes dados as informações através do site da Instituição do Ensino Superior.
} 
processo de ensino e aprendizagem pertinente aos envolvidos. Cruz e Cavalcante (2018, p. 81) afirmam: «Ao professor cabe uma preocupação constante com a elaboração e renovação da própria formação, articulando e refletindo sobre os princípios e processos desta formação, levando em conta o campo de atuação, com o desafio de pensar princípios e processos formativos.»

Entender o contexto formativo é perceber os caminhos do fazer docente e saberes que imbricam o fazer pedagógico, em especial nos cursos de licenciatura. Segundo a Lei de Diretrizes e Bases da Educação - LDB (nº 9.394/1996) que estabelece as diretrizes e bases da educação nacional, dialogando com as demais políticas públicas como as Diretrizes Nacionais de Educação - DCN's e o Plano Nacional de Educação - PNE. A LDB compreende e estabelece nos seus incisos a formação específica para os professores que atuam na educação básica e, para os professores do ensino superior afirma no artigo 66: «A preparação para o exercício do magistério superior far-se-á em nível de pósgraduação, prioritariamente em programas de mestrado e doutorado» (Lei n. 9.394, 1996, p. 21). Assim, a formação destes professores fica a cargo dos cursos de lato sensu e de stricto sensu, percebendo a responsabilidade desses processos formativos na constituição desse professor universitário, mas ressaltando a necessidade específica de uma formação inicial e continuada para os caminhos pedagógicos do exercício docente. Segundo Imbernón (2000, p. 71):

«O conhecimento profissional consolidado mediante a formação permanente apoia-se tanto na aquisição de conhecimentos teóricos e de competências e rotinas como no desenvolvimento de capacidades de processamento da informação, análise e reflexão crítica em, sobre a durante a ação, o diagnóstico, a decisão racional, a avaliação de processos e a reformulação de projetos.»

Dialogando com os estudos de Imbernón e indo ao encontro das DCN's para o curso de Pedagogia, temos a Resolução CNE/CP n ${ }^{\circ}$, de 15 de maio de 2006, Parágrafo único. Para a formação do licenciado em Pedagogia são pontos centrais:

«I- o conhecimento da escola como organização complexa que tem a função de promover a
educação para e na cidadania;
II- a pesquisa, a análise e a aplicação dos resultados de investigações de interesse da área
educacional;
III- a participação na gestão de processos educativos e na organização e funcionamento de
sistemas e instituições de ensino.» (Resolução CNE/CP n. 01,2006 , p. 01).

Dessa forma percebemos a necessária intenção pedagógica dos conhecimentos teóricos e práticos pautados na contribuição da formação para os licenciando em Pedagogia e a pertinência de uma formação dos professores que contribua para essa construção do conhecimento. E dialogando com o Projeto Pedagógico do Curso de Pedagogia EaD - IES, percebemos que um dos seus principais objetivos é

«oferecer formação inicial, em nível de graduação, para professores pedagogos contribuindo para a compreensão crítica de concepções que fundamentam a docência na educação infantil, nos anos iniciais do ensino fundamental e gestão escolar, bem como para uma atuação consciente no debate político, teórico e didático-metodológico relativo ao campo da educação» (UECE, 2017, p. 49).

Diante do exposto, percebe-se a preocupação formativa do curso de licenciatura na modalidade EaD com o diálogo das DCN's para o curso de Pedagogia, como também em consonância com a finalidade pedagógica do curso presencial, que tem como objetivo principal preparar os discentes para a docência na educação infantil e nos anos iniciais do ensino fundamental de forma condizente com resoluções e regulamentação da profissão. (UECE/CED, 2011). Pimenta, Fusari, Pedroso e Pinto (2017) observam que o curso de Pedagogia não se restringe somente à docência, há um amplo campo de atuação profissional para o licenciado em Pedagogia que excede significativamente o exercício da docência, em especial quando se propõe a preparar esse professor para a área da gestão educacional e atuação em espaços não escolares. 
Cruz e Cavalcante (2018) ressaltam sobre a expansão democrática no ensino superior junto com os avanços tecnológicos, as possibilidades docentes formativas para os licenciados e a contribuição da modalidade EaD para esta constituição formativa. Desse modo as autoras ressaltam que

\begin{abstract}
«é no cenário de democratização e expansão do ensino superior, em especial, da formação de professores da $\mathrm{EaD}$, que se observa a necessidade de se pensar nos desafios da formação desses professores, em particular do pedagogo. [...] Nota-se que se exige desse professor uma posição pró-ativa ante às manifestações da Educação, em constantes circunstâncias de mudanças e que recebe diretamente a interferência do meio. A EaD, nessa perspectiva, conquista cada dia seu espaço, com destaque para os cursos de graduação, em especial, as licenciaturas e Pedagogia, evidenciando as novas possibilidades do ensino-aprendizagem.» (Cruz \& Cavalcante, 2018, p. 71).
\end{abstract}

$\mathrm{E}$, assim, nos faz refletir sobre o espaço formativo que a $\mathrm{EaD}$ ao longo dos anos vem construindo e a necessidade de se pensar sobre a formação daqueles que atuam como professores e tutores na educação a distância, percebendo a implicância nos processos educativos.

A formação continuada dos professores é a necessidade reflexiva de nós educadores estarmos em processos formativos formais e informais, é buscar levando em consideração as novas realidades situações e concepções que nos ajudem na prática docente, principalmente, ao discorremos sobre os profissionais do ensino superior que trabalham nos cursos de educação a distância, em especial no curso de Pedagogia. É entender um repertório de conhecimentos acerca do fazer docente nos cursos de licenciatura, mas é também entender as novas demandas educacionais, sociais e políticas, é motivar-se a compreender novos recursos tecnológicos em ambientes virtuais que possam contribuir no processo formativo dos novos docentes. Segundo Jardilino e Sampaio (2019) é importante frisar que, ao conceber o desenvolvimento profissional como processo que ocorre ao longo da vida docente, rompe-se com a propensão em não se dar a devida importância ao que vem após a formação inicial.

Assim, a formação continuada precisa ser imbricada no seu constante "ser professor", entendendo as especificidades do seu lócus de ensino, neste caso a EaD. Conforme Farias, Sales, Braga e França (2014, p. 61), «a formação é um dos contextos de socialização que possibilita ao professor reconhecerse como um profissional, constituindo-se como base nas suas relações com os saberes e com o exercício da docência».

$\mathrm{Na}$ seção seguinte, apresentaremos os docentes universitários que ministram as disciplinas no curso de Pedagogia UAB/UECE.

4. Docentes universitários no curso de Pedagogia da UAB: mapeando as trajetórias de formação

Para o início da coleta de dados, realizamos contato com a coordenação do curso de Pedagogia da UAB para esclarecimentos sobre o objetivo e desenvolvimento da pesquisa. Após a autorização para termos acesso à lista com os nomes dos professores da turma das disciplinas selecionadas, foram solicitados contatos de endereço de e-mail e telefones. Para acesso aos dados sobre formação complementar, inicial e continuada, optamos pela pesquisa nos currículos lattes dos professores.

Foram mantidas em sigilo a identificação dos professores. Sendo assim, cada docente está representado por um número de 1 a 5 nas duas disciplinas pesquisadas, identificando Avaliação Educacional como disciplina (1) e Didática Geral como disciplina (2). Pelas informações contidas nos currículos lattes, foi feito o mapeamento da formação inicial e continuada dos sujeitos, para a qual foram consideradas pós-graduação lato e stricto sensu.

Quadro 2.

Formação inicial e pós-graduação dos professores da disciplina 1 e 2 Disciplina 1

\begin{tabular}{|c|c|c|c|c|}
\hline $\mathrm{N}^{\mathrm{o}}$ & Graduação & Especialização & Mestrado & Doutorado \\
\hline 1 & Pedagogia & Não informado & Linguística & Não informado \\
\hline
\end{tabular}




\begin{tabular}{lllll}
\hline 2 & Não informado & Orientação educacional & Não informado & Não informado \\
\hline 3 & Ciências Sociais & Educação Brasileira & Políticas Públicas & Não informado \\
\hline 4 & $\begin{array}{l}\text { Ciências Sociais e } \\
\text { História }\end{array}$ & Metodologia da pesquisa & Educação & Não informado \\
\hline 5 & $\begin{array}{l}\text { Pedagogia e Matemá- } \\
\text { tica }\end{array}$ & Gestão Educacional & Ciências & Não informado \\
\end{tabular}

\begin{tabular}{|c|c|c|c|c|}
\hline \multicolumn{5}{|c|}{ Disciplina 2} \\
\hline $\mathrm{N}^{\mathrm{o}}$ & Graduação & Especialização & Mestrado & Doutorado \\
\hline 1 & Pedagogia & Metodologia & Educação & Educação \\
\hline 2 & História & Metodologia & História & Educação \\
\hline 3 & Pedagogia & Psicopedagogia & Saúde coletiva & Não informado \\
\hline 4 & Pedagogia & Formação de professores & Não informado & Não informado \\
\hline 5 & Estudos Sociais & Planejamento Educacional & Gestão Educacional & Não informado \\
\hline
\end{tabular}

Fonte: elaborado pelos autores.

Em relação a formações na área pedagógica, na qual consideramos formações pedagógicas todas aquelas relacionadas à educação e ao ensino, dentre os 10 docentes pesquisados, 5 professores possuem formação inicial em Pedagogia, 4 em licenciaturas nas áreas da Ciências Sociais, História, Matemática e Estudos Sociais e 1 não foi identificado.

Quando nos referimos a formações em nível de graduação, especialização, mestrado e doutorado, constatamos que dos 10 professores analisados 9 possuem graduação registrada no lattes, 9 com especialização, 8 com mestrado e 2 com doutorado. Observamos que todos os professores pesquisados apresentam alguma formação na área da educação. Dessa forma entendemos a trajetória profissional destes professores ao optar por lecionar na formação inicial no curso de licenciatura e suas formações, estes apresentam pós-graduação lato ou stricto sensu na área educação, mas não apresentam especificidades sobre EaD. Outro aspecto investigado destinou-se à formação complementar dos professores, também utilizando os currículos lattes como fonte, buscando identificar cursos de curta duração relacionados ao exercício profissional para a docência, e mais especificamente para a EaD. Para apresentação dos dados sobre formação complementar, elaboramos o quadro a seguir.

Quadro 3.

Lista de sujeitos e quantidade de formações complementares

\begin{tabular}{llll}
\hline Professor & $\begin{array}{l}\text { Quantidade de forma- } \\
\text { ções complementares } \\
\text { em Educação }\end{array}$ & $\begin{array}{l}\text { Quantidade de Formações } \\
\text { complementares em EaD }\end{array}$ & $\begin{array}{l}\text { Carga horária de cur- } \\
\text { sos na área da EaD }\end{array}$ \\
\hline
\end{tabular}

Disciplina 1

\begin{tabular}{llll}
\hline Professor A1 & 0 & 0 & 0 \\
\hline Professor A2 & 3 & 1 & $160 \mathrm{~h}$ \\
\hline Professor A3 & 4 & 0 & 0 \\
\hline Professor A4 & 15 & 3 & $340 \mathrm{~h}$ \\
\hline Professor A5 & 1 & 0 & 0 \\
\hline
\end{tabular}

Disciplina 2

\begin{tabular}{llll}
\hline Professor D1 & 2 & 0 & 0 \\
\hline Professor D2 & 28 & 0 & 0 \\
\hline Professor D3 & 1 & 0 & 0 \\
\hline Professor D4 & 2 & 0 & 0 \\
\hline Professor D5 & 2 & 0 & 0 \\
\hline
\end{tabular}


Fonte: elaborado pelos autores.

Percebeu-se durante a realização da pesquisa nos currículos lattes que 9 docentes pesquisados registraram formações complementares, no entanto somente 2 desses docentes correspondem à formação complementar voltada para atuação na modalidade de $\mathrm{EaD}$, campo em que atuam. Para Junges, Ketzer e Oliveira (2018), na formação continuada, o docente precisa ter a oportunidade de recriar suas práticas. Segundo os autores, deve ser o sujeito que, junto com a formação, irá contribuir para as mudanças necessárias na sociedade, visto que uma prática singular poderá ser determinante para a transformação da qualidade de ensino.

Uma dificuldade encontrada na busca das informações nos lattes foi a falta de assiduidade com a qual os docentes atualizam as informações, principalmente no que diz respeito aos cursos de formação complementar. Essa ausência de atualização por parte dos professores resulta inicialmente da dificuldade em manusear a Plataforma Lattes relatada por estes em entrevistas informais e nos momentos formativos, como no curso básico de preenchimento do Lattes, anualmente promovido pela Pró-reitora de Pós-Graduação e Pesquisa durante a semana universitária da instituição.

Nos currículos analisados, percebeu-se escassos registros de informações referentes a participação em formações ou cursos com ênfase na modalidade a distância ou em Ambientes Virtuais de Aprendizagem. Os dois docentes que apresentaram formações complementares que foram identificadas a partir de algumas palavras-chave: Tutoria a distância; EaD ou Informática Educativa somam a carga horária descrita no QUADRO 3 em epígrafe.

Desse modo, nos certificamos destas informações com a coordenação do curso da instituição. Foi evidenciado também durante a pesquisa que não existe uma política de formação continuada aos docentes que atuam na educação a distância. E compreendemos esse aspecto como política educacional necessária para a fomentação de saberes para a prática docente.

Destacamos que ao assumir a docência universitária em um curso em EaD, desde o início da carreira, é responsabilidade do professor presencial junto com o professor conteudista. O documento do Projeto Pedagógico do Curso (PPC), de 2016, do Curso de Pedagogia analisado neste estudo define "Professor conteudista" como responsável pela produção de módulos/livros para as disciplinas, fruto de iniciativas acadêmicas de pesquisa e produção intelectual para serem utilizados nos cursos oferecidos pela Instituição demandante. Planejar, ensinar, escolher as estratégias e recursos didáticos e avaliar. Em alguns casos é atividade individual por não contar com o apoio dos professores mais experientes e sem espaços institucionais voltados para a constituição dos conhecimentos relativos ao ser professor. Porém, é preciso ressaltar que «quando os professores trabalham juntos, cada um pode aprender com o outro. Isso os leva a compartilhar evidências e informação e a buscar soluções» (Imbernón, 2000, p. 78).

A relevância desta pesquisa, portanto, configurou-se em mapear a formação inicial, continuada e complementar, relacionadas às disciplinas que ministram e a modalidade em que atuam, buscando, assim, corroborar com os escritos de Tardif (2008), que afirma, tanto em suas bases teóricas quanto em suas consequências práticas, que os conhecimentos profissionais são evolutivos e progressivos e necessitam, por conseguinte, de uma formação continuada.

Diante desses resultados, destacamos que a formação dos professores precisa ser constante para além da formação inicial e continuada, articulando o processo pedagógico e didático. De acordo com Imbernón (2000, p. 71):

«A formação permanente não deve oferecer apenas novos conhecimentos científicos, mas principalmente processos relativos a metodologias de participação, projetos, observação e diagnóstico dos processos, estratégias contextualizadas, comunicação, tomada de decisões, análise da interação humana.»

Assim, interiorizando conhecimentos específicos do campo da educação e no contexto da formação de professores, destacamos que é imprescindível que as instituições de ensino superior compreendam a formação dos docentes como um investimento institucional prioritário, tendo em vista que em algumas IES encontramos a insuficiência ou inexistência de ações formativas permanentes que agreguem valor ao trabalho dos professores em todas as suas dimensões. 
Dessa forma, pensar na formação dos professores é refletir sobre a sua trajetória profissional como também aliar há uma formação continuada que mobilize conhecimentos específicos sobre os conteúdos e da ação docente.

\section{Considerações finais}

Conforme os resultados desta pesquisa, a atuação no curso e nas disciplinas ofertadas na modalidade EaD no curso de Pedagogia da UAB/UECE, exige algumas especificidades no seu trabalho pedagógico. O docente que atua no curso pesquisado e não somente deve possuir o domínio do conteúdo, mas também saber o efetivo funcionamento de cada ferramenta contida no Ambiente Virtual de Aprendizagem para poder planejar suas atividades no transcorrer das aulas, além das especificidades da ação docente durante o processo de ensino e aprendizagem.

A modalidade presencial apresenta um cenário em que o professor possui autonomia na execução de suas propostas avaliativas. Na modalidade a distância, o docente se depara com algumas dificuldades referentes ao que está posto na plataforma e é necessária uma reflexão com o ensino e a constituição que compõem essa modalidade educacional.

Percebido em nosso estudo ao utilizarmos os dados quantitativos deste mapeamento sobre a formação dos professores, nos ajuda a refletir os caminhos da trajetória profissional destes docentes, em especial os possíveis caminhos para uma formação continuada que atrele as discussões e conhecimentos sobre educação a distância como pertinente neste trabalho docente.

Ao nos determos aos dados extraídos dos lattes dos sujeitos pesquisados e com a coordenação do curso de Pedagogia, percebemos um grupo heterogêneo, mas com características similares quando pesquisamos sobre suas formações no tocante à educação a distância.

Concluímos que a formação dos professores do curso de Pedagogia da UAB/UECE e o seu percurso formativo constituem-se como essenciais na atuação docente, e neste estudo relativo às compreensões teóricas e práticas na modalidade educacional, o nosso objetivo foi de mapear o percurso formativo dos professores do curso de Licenciatura em Pedagogia da UAB foi alcançado, nos permitindo realizar uma reflexão sobre as trajetórias profissionais e a constituição do "ser professor".

Destacamos a necessidade de pensar em uma política de formação continuada aos professores em exercício docente, bem como contribuir para as discussões sobre a docência nas instituições de ensino.

Evidencia-se, portanto, a relevância desta pesquisa demonstrando a necessidade de estimular e promover formações para os docentes que atuam especificamente na modalidade a distância e reforçar a pertinência de uma formação contextualizada com a sua prática, compreendendo os princípios da avaliação como componente do processo de ensino e aprendizagem do discente, possibilitando uma atuação cada vez mais eficaz.

\section{Referências}

Almeida, M. E. B. (2003). Educação a distância na internet: abordagens e contribuições dos ambientes digitais de aprendizagem. Educação e Pesquisa, 29(2), pp. 327-340. doi: 10.1590/S151797022003000200010

Bogdan. R., \& Biklen, S. (1994). Investigação Qualitativa em Educação. Porto: Porto.

Costa, L. A. C., \& Franco, S. R. K. (2005). Ambientes virtuais de aprendizagem e suas possibilidades construtivistas. Novas Tecnologias na Educação, 3(1). doi: 10.22456/1679-1916.13781

Cruz, M. V. T., \& Cavalcante, M. M. D. (2018). Experiências de EaD em cursos de Pedagogia do Ceará: um olhar sobre a matriz curricular. Curitiba: Appris Editora.

Dal-Farrs, R. A., \& Lopes, P. T. C. (2013). Métodos mistos de pesquisa em educação: pressupostos teóricos. Nuances: estudos sobre Educação, Presidente Prudente-SP, 24(3), pp. 67-80. doi: 10.14572/nuances.v24i3.2698

Depresbiteris, L. (1999). Avaliação educacional em três atos. SENAC.

Decreto $n^{\circ} 5.800$ de 8 de junho de 2006. Dispõe sobre o Sistema Universidade Aberta do Brasil-UAB. Recuperado de http://www.planalto.gov.br/ccivil_03/_Ato2004-2006/2006/Decreto/D5800.htm

Farias, I. M. S., Sales, J. O. C. B., Braga, M. M. S. C., \& França, M. S. L. M. (4a ed.). (2014). Didática e docência aprendendo a profissão. Brasília: Liber Livro. 
Freire, P. (2006). Pedagogia da autonomia: saberes necessários à prática educativa. (34ª ed.). São Paulo: Paz e Terra.

Freire, P. (1970). Pedagogia do oprimido. Rio de Janeiro: Paz e Terra.

García, C. M. (1999). Formação de Professores: Para uma mudança educativa. Coleção Ciências da Educação século XXI. Porto: Porto Editora.

Gauthier, C., Mortineau, S., Desbiens, J-F., Malo, A., \& Simard, D. (1998). Por uma teoria da Pedagogia: pesquisas contemporâneas sobre o saber docente. Ijuí: Unijuí.

Gil, A. C. (2002). Como elaborar projetos de pesquisa. (4a ed.). São Paulo: Atlas.

Imbernón, F. (2000). Formação Docente e Profissional: forma-se para a mudança e a incertez̧a. São Paulo: Cortez.

Jardilino, J. R. Lima., \& Sampaio, A. M. M. (2019). Desenvolvimento profissional docente: reflexões sobre política pública de formação de professores. Educação \& Formação, 4(10), pp. 180-194. doi: 10.25053/redufor.v4i10.848

Johnsin, R.B., Onweugbuzie, A. J., \& Turner, L. A. (2007). Toward a definition of mixed methods research. Journal of Mixed Methods Research, 1(2), pp. 112-133. doi: 10.1177/1558689806298224

Junges, F. C., Ketzer, C. M., \& Oliveira, V. M. A. (2018). Formação continuada de professores: saberes ressignificados e práticas docentes transformadas. Educação \& Formação, 3(9), pp. 88-101. doi: 10.25053 /redufor.v3i9.858

Lei n. 9.394, de 20 de dezembro de 1996. Lei de Diretrizes e Bases da Educação. Estabelece as diretrizes e bases da educação nacional. (13 ${ }^{\mathrm{a}}$ ed.). Brasília: Câmara dos Deputados. Recuperado de https://www.planalto.gov.br/ccivil_03/leis/19394.htm

Moraes, M. C. (Org.). (2002). Educação a distância: fundamentos e práticas. São Paulo, Unicamp/NIED.

Pimenta, S. G., Fusari, J. C., Pedroso, C. C. A., \& Pinto, U. A. (2017). Os cursos de licenciatura em pedagogia: fragilidades na formação inicial do professor polivalente. Educação e Pesquisa, 43(1), pp. 15-30. doi: 10.1590/s1517-9702201701152815

Resolução CNE/CP n. 01, de 15 de maio de 2006. Institui as Diretrizes Curriculares Nacionais para o Curso de Pedagogia, Licenciatura. Recuperado de https://portal.mec.gov.br/cne/arquivos/pdf/rcp01_06.pdf

Rocha, C. M. F. (2006). As "novas" tecnologias e o(s) dispositivo(s) de controle. In: L. H. Sommer, \& M. I. E. Bujes (Orgs.). Educação e cultura contemporânea: articulações, provocações e transgressões em novas paisagens. Canoas: Ed. Ulbra.

Sampaio, M. N., \& Leite, L. S. (1999). Alfabetização tecnológica do professor. Petrópolis: Vozes.

Silva, A. (2006). Processos de ensino-aprendizagem na era digital. O Professor (93). Portugal: Editorial Caminho. Recuperado de https://www.bocc.ubi.pt/_listas/tematica.php?codtema=2

Silva, M. (Org). (2a ed.). (2006). Educação online: teorias, práticas, legislação e formação corporativa. São Paulo: Loyola.

Schön, D. A. (2000). Educando o profissional reflexivo: um novo design para o ensino e a aprendizagem. Porto Alegre: Artés Médica Sul.

Tardif, M. (17 ed.). (2008). Saberes docentes e formação profissional. Petrópolis: Vozes.

Tavares, K. C. A. (2001). O professor virtual: reflexões sobre seu papel e sua formação. Recuperado de https://www.lingnet.pro.br/papers/eadprof.htm

Universidade Estadual do Ceará. (2011). Projeto Pedagógico do Curso de Licenciatura em Pedagogia. Fortaleza: UECE.

Universidade Estadual do Ceará. (2017). Projeto Pedagógico do Curso de Licenciatura a Distância (UAB) em Pedagogia. Fortaleza: UECE.

Vidal, E. M., Maia, J. E. B., \& Gomes, E. P. (1ª ed.). (2014). Introdução à Educação. UAB/UECE. Fortaleza.

Ventura, M. M. (2007). O Estudo de Caso como Modalidade de Pesquisa. Pedagogia médica. Rev SOCERJ, 20(5), pp. 383-386.

Yin, R. K. (5 ${ }^{\mathrm{a}}$ ed.). (2015). Estudo de caso: planejamento e métodos. Porto Alegre: Bookman. 